\title{
Paruthi Paal, a nutrient-rich healthy drink from cottonseed: an Indian delicacy
}

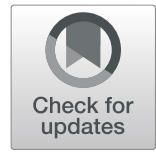

Manoj Kumar(D

\begin{abstract}
Paruthi Paal is a very nutritious drink that is very much popular in the Tamil Nadu state of India. Paruthi Paal is regarded as "triple-nutrient" as it is a very rich source of protein, essential fatty acids, and sugars and can be called as an energy drink. The present paper will be focussed on developing a process protocol for the preparation of the nutrient-rich product "Paruthi Paal" from the traditional knowledge available. The paper also focusses on typical ingredients required for making this healthy drink. Further, this paper will present various health benefits of cottonseed which includes healing of stomach ulcer, regulation of menstrual cycle, curing cold and cough, maintaining blood pressure and also acting as an antioxidant. Overall, the study leads to a development of a protocol and a traditional delicious product (Paruthi Paal) with a view to popularise among other parts of the globe.
\end{abstract}

Keywords: Cottonseed milk, Paruthi paal, Ethnic drink, Nutritious

\section{Introduction}

Cotton is mainly cultivated as a fibre crop which is considered as the main economical part. After the removal of fibre after ginning, the seed cotton was left with the most important by-product cottonseed. Cottonseed oil $(20-22 \%)$ contains unsaturated fatty acids and considered as a healthy oil. It is used for frying, salad dressing and also blending with other oils such as soybean, groundnut and sunflower oil to improve their quality with respect to flavour stability. Apart from healthy oil, cottonseed also contains a good quantity of protein (20$25 \%)$ with some phenolic compounds which impart antioxidant property to protein component. These essential components of cottonseed can be utilised as a source of nutrition in cotton-growing countries. Tanzania, Uganda, Zimbabwe, Burkina Faso, Zambia, and other ten countries of African subcontinent depend on cotton earnings and its crucial source of income for farmers and their families. These countries also face menace of malnutrition and energy malnutrition. Hence, cottonseed, if utilised as a food supplement, can play a crucial role to overcome these problems in a cost-effective manner.

This paper will give insights on ethnic food which is traditionally a speciality of "Tamil Nadu" state of India (Fig. 1).

Correspondence: manojkumarpuniya114@gmail.com

Chemical and Biochemical Processing Division, ICAR-Central Institute for Research on Cotton Technology, Mumbai 400019, India
This delicious drink is popularly known as Paruthi Paal (Paruthi means cottonseed and Paal means milk). Paruthi Paal is regarded as "triple-nutrient" as it is a very rich source of protein, essential fatty acids and sugars and can be called as an energy drink. The history of consumption cottonseed as a source of energy or Paruthi Paal is not so rich. However, at the time of World War II due to the unavailability of most of the other edible sources, various products made from the cottonseed were served to the soldiers [1]. This started the use of the cottonseed consumption in the modern era. This article will explain the detailed protocol for the preparation of Paruthi Paal and also about its beneficial effects. These beneficial effects are mainly discussed based on the traditional knowledge of local people. The gossypol, a toxic phenolic compound having anti-nutritive value present in the cottonseeds, must be removed to make cottonseed milk fit for human consumption. So, it is preferred to use glandless seed which do not have the risk of gossypol.

\section{Paruthi Paal}

For extraction of milk, cottonseeds need to be washed and then soaked in water for overnight. After soaking, seeds were blended with the help of a blender or mixer, and later on, the blended material is kept on a muslin cloth and the filtrate is collected in a jar. The proximate analysis of cottonseed reported to have $23.1 \mathrm{~g}$ of protein, $22.9 \mathrm{~g}$ fat, $43.2 \mathrm{~g}$ carbohydrates, $7.3 \mathrm{~g}$ moisture and $3.5 \mathrm{~g}$ 


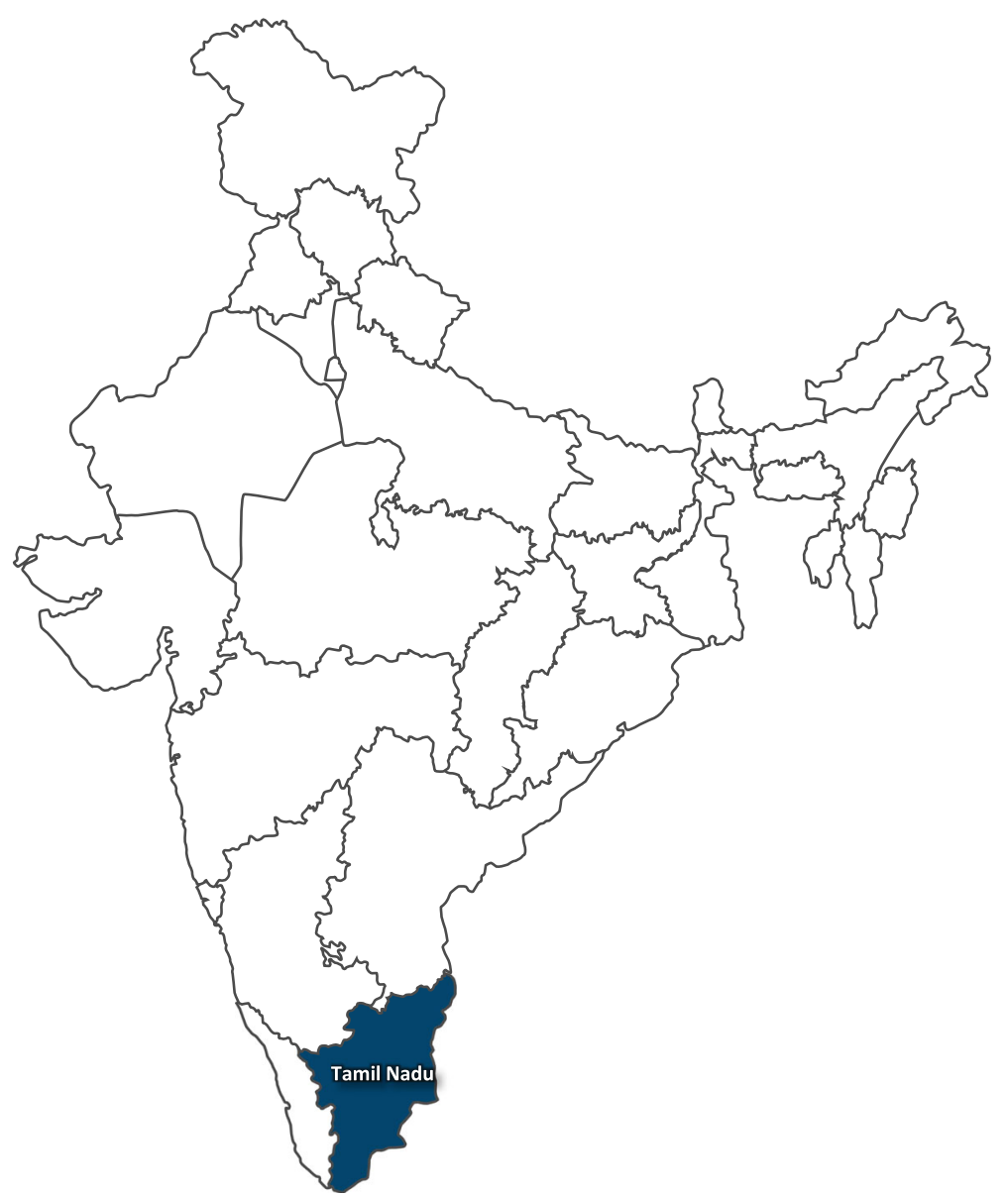

Fig. 1 Map showing the consumption of Paruthi Paal in Tamil Nadu, India

of minerals per $100 \mathrm{~g}$ of cottonseed [2]. After popularisation of beneficial effects of cottonseed milk, various edible products have been developed indigenously by localites of Tamil Nadu state. These food products include tamucurd, cheese, curd, yogurt, ice-creams, sausage type meet, cottonseed soup (Nigeria), chocolates, biryani and paruthi halwa. Paruthi Paal is the best remedy for cold and cough; it cools the body and very good for the nursing mother. Also, it is a very good alternative for cow's milk so it can be had by people having lactose intolerance. Many districts in Tamil Nadu serve Paruthi Paal as a welcome drink to their guests. It is believed to have high density cholesterol (good cholesterol) and flush out low density lipoprotein (bad cholesterol), reduce the risk of cardiovascular diseases, improve the neurological health, reduce body heat, ensure good functioning of pancreas, improve blood circulation and digestion and also report to induce good sleep. Jaggery is usually added for sweetness. Cottonseed milk can be a nutritious innovative drink with added jaggery or $2 \%$ sucrose solution and $0.2 \%$ of common salt. The addition of sucrose and jaggery further improves the taste of cottonseed milk. Strawberry or sitaphal pulp is also added in cottonseed milk for enhancing its taste, flavour and consistency. The heating of cottonseed milk at $70-80^{\circ} \mathrm{C}$ for $10-15 \mathrm{~min}$ will lead to its pasteurisation. It is also a very good alternative to cow or buffalo milk with respect to acidity, viscosity and total solid content. The physicochemical property and sensory characteristics are acceptable and comparable with the commercial powdered cow's milk [2]. The total solid content in cottonseed milk ranges from $11.8 \%$ to $13 \%$, acidity varies from $0.17 \%$ to $0.19 \%$ (lactic acid $\mathrm{g} / 100 \mathrm{ml}$ ), $\mathrm{pH}$ ranges from 6.5 to 7.1 and viscosity from 2.8 to $3.4 \mathrm{cP}$ [2]. Recently, cottonseed milk has also been used in the cosmetic industry for making moisturising lotions, shampoos, conditioners, skin creams, herbal medicine, etc., and these products are available commercially in the market [2]. Cottonseed milk is very famous in Madurai (Tamil Nadu). The milk extracted from the cottonseed is the main ingredient for Paruthi Paal. In the next section, we will see the detailed process of "Paruthi Paal" preparation. 


\section{Protocol for preparation Paruthi Paal}

Ingredients (servings, 8-10)

Ingredients include cottonseeds (Paruthi) (one tumbler (glass)), rice/kudu millet (one-fourth tumbler (glass)), jaggery (one tumbler (glass)), cardamom powder (onefourth tsp), coconut milk (one tumbler (glass)), grated coconut (one-half tsp)/coconut milk and dry ginger powder (one-fourth tsp) (Fig. 2).

\section{Preparation}

Soak the cottonseeds overnight and wash them in running water by picking out the cotton and mud sticking to them. Continue cleaning in running water for 3 to 4 times. Extract milk from cottonseeds by adding a little water to it and blending in the blender for a minute. Strain the milk from it using a muslin cloth or strainer. Then again, pour a cup of water and blend it again and filter the milk from cottonseed mash (Fig. 3). Similarly, extract milk from the coconut milk (Fig. 4c) and make jaggary syrup. Syrup can be made by crushing the jaggery and take it in a pan with water (to dissolve the jaggery), keep in medium flame, until it comes to syrup consistency (Fig. 5). Filter it and keep it aside.

Pour the filtered cottonseeds milk in a pot and start heating it, stir once in a while, until it starts boiling. Keep in low flame for $5 \mathrm{~min}$, once it starts boiling and keep on stirring. Take rice flour in a cup or kodu millet flour, pour in a cup of water and stir it well, so that no lumps are formed or make a paste with almonds as shown in Fig. 4a, b. Now pour this to the boiling cottonseed milk and continue stirring, or else lumps would be formed. Crush the cardamom pods and keep it aside. Add in cardamom powder, cardamom pods, ginger powder and continue stirring, until it thickens. Pour

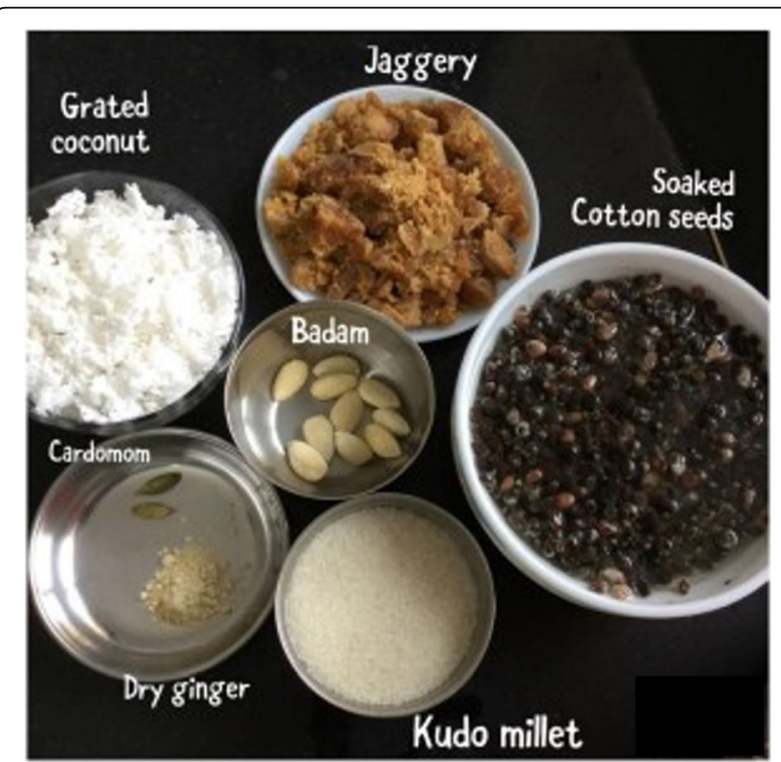

Fig. 2 Ingredients of Paruthi Paal preparation in the jaggery syrup, keep in medium flame for $5 \mathrm{~min}$ and keep on stirring every now and then until it thickens. Keep in low flame and pour in the coconut milk and keep on stirring until the raw smell goes off. Remove from fire and serve hot in morning (Fig. 6). This can also prepared with few herbal spices as a herbal drink which is good for cold, cough and digestion.

\section{Beneficial effects of Paruthi Paal}

Here is a list of health benefits:

\section{Heals stomach ulcer}

Various factors and eating habit leads to disturbance of environment of stomach and leads to stomach ulcers. The most common cause of stomach ulcer is Helicobacter pylori bacteria. Consumption of Paruthi Paal has proven to be a traditional way to overcome the problem of stomach ulcers. It might be due to inhibition of activity of Helicobacter pylori bacteria [3].

\section{Prevents polycystic ovary syndrome}

Polycystic ovary syndrome (PCOS) can also lead to other serious health challenges, such as diabetes, cardiovascular problems, depression and increased risk of endometrial cancer [4]. Controlling the diabetic condition by consuming low-calorie or low-glycaemic index foods such as legumes, seeds, nuts and fruits. Cottonseed is also considered as a low-glycaemic index and have beneficial effects in preventing PCOS. Secondly, cottonseed is also a very good source of magnesium and shown good results in the prevention of PCOS [5].

\section{Regulates menstrual cycle}

The management of menstrual cycle can be also be regulated by consuming low carbohydrate diet as discussed in PCOS section [6].

\section{Remedy for cold and cough}

A concoction of cottonseed milk, ginger, cardamom and almonds for making Paruthi Paal is preferred a source for treating cold and cough in Tamil Nadu.

\section{Ease in labour pains}

The concoction of cottonseed and root of cotton stimulates uterine contraction and leads in preventing the labour pains [6].

\section{Antioxidant benefits}

Lipids in cottonseed are known to have an excellent source of antioxidants which are known to be very important in maintaining human health and helps in removing reactive oxygen species generated in the body and have anti-ageing effects [7]. 

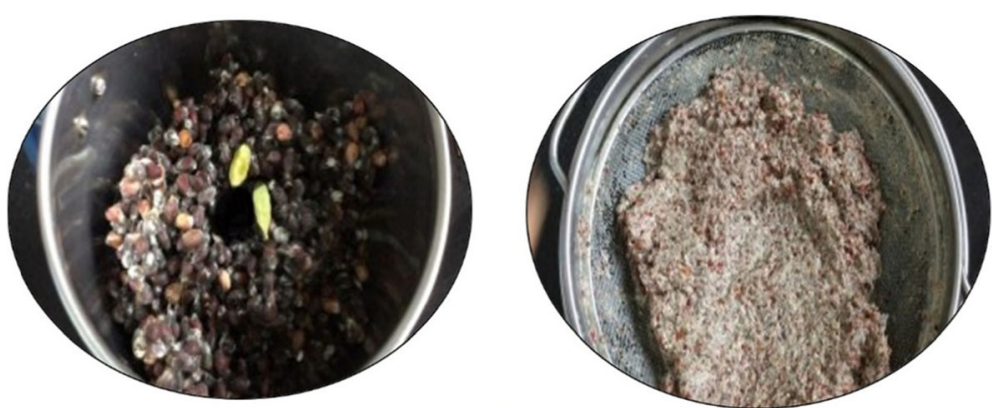

(A)

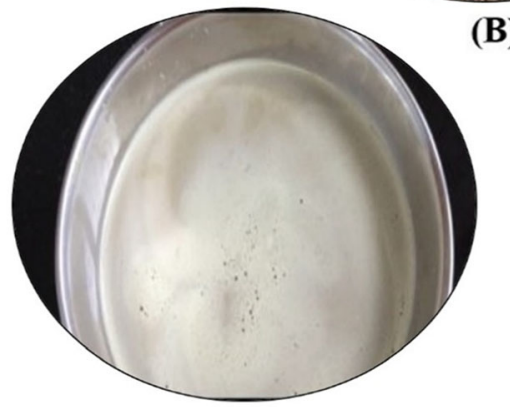

(B)

(C)

Fig. 3 Process of cottonseed milk preparation. In the process of developing a suitable protocol for the preparation of Paruthi Paal, first and most, the critical step is the preparation of cottonseed milk by following a simple process: a soaking cotton seeds and cardamom overnight, $\mathbf{b}$ grinding and filtering the extract using a mixer and sieve, respectively (husk in the sieve can be seen in the $\mathbf{b}$ ), $\mathbf{c}$ the filtrate, popularly known as cottonseed milk

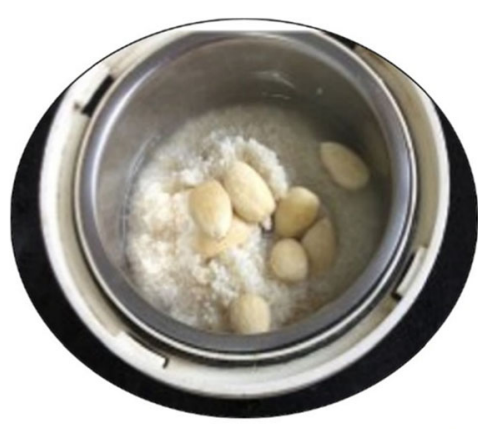

(A)

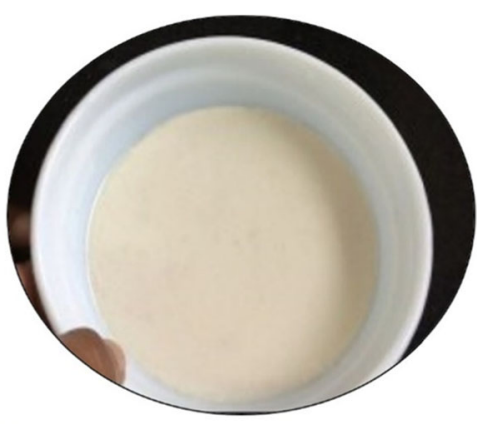

(B)

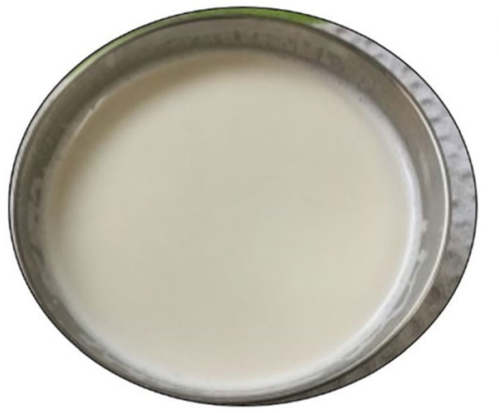

(C)

Fig. 4 Process of rice flour/kodu millet paste and coconut milk preparation. The paste can be made either by the use of rice flour or kodu millet or by mixture of both. Rice flour results in the development of high glycaemic index Paruthi Paal where kodu millet is traditionally used as anti-diabetic or low glycaemic index source. Rice flour or kudo millet and almond mixture can be seen in $\mathbf{a}$. $\mathbf{b}$ Making paste from rice flour or kudo millet and almond. c Coconut milk: it was prepared in a similar way as showed in Fig. 2 for the preparation of cottonseed milk 


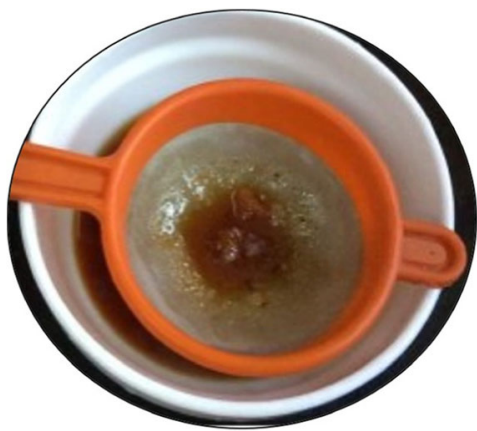

(A)

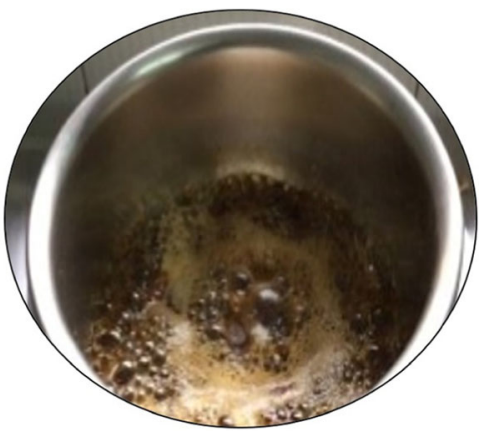

(B)

Fig. 5 Preparation of jaggery. To impart a sweet and pleasant taste to Paruthi Paal, jaggery is added. In a, boiling and filtering the jaggery. $\mathbf{b}$ filtered jaggery syrup

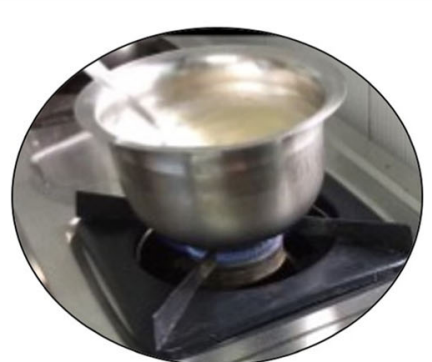

(A)

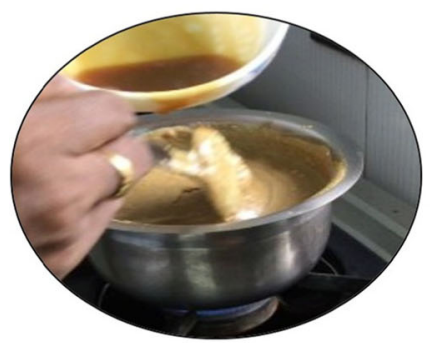

(C)

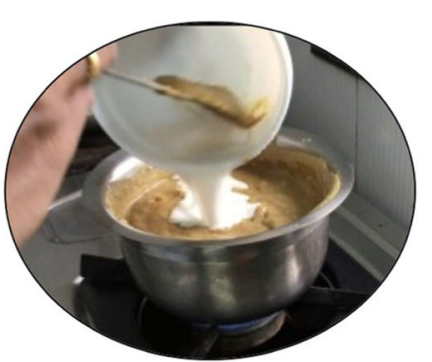

(B)

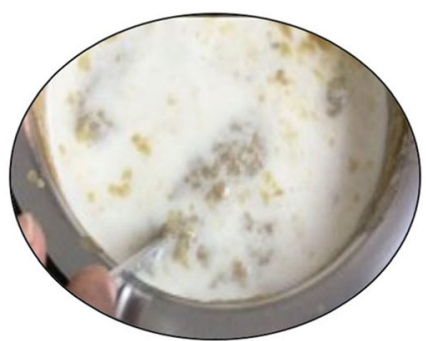

(D)

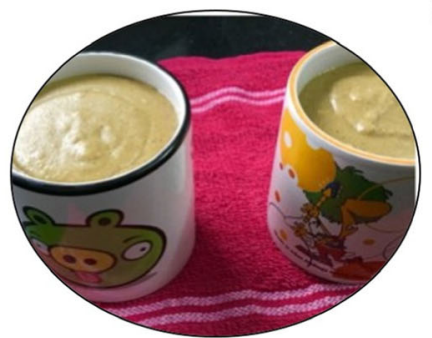

(E)

Fig. 6 Process of Paruthi Paal preparation. In the protocol for the preparation of Paruthi Paal, first a Boiling cottonseed milk obtained in Fig. 3. b Addition of rice/kodu millet paste prepared in Fig. 4. c Addition of jaggery syrup prepared in Fig. 5. d Addition of coconut milk and mixed well. e Ready to serve Paruthi Paal 


\section{Cholesterol benefits}

Cottonseed consumption has been seen to increase the amount of HDL, also known as the good cholesterol in the body and help in reducing the impact of LDL or the bad cholesterol levels in the human body too. This is due to the fact that cottonseed oils are rich in oleic acid which helps to boost the activity of HDL in the long run [7].

\section{Helps prevent cancers}

Cottonseed oil is considered one of the great vegetable oils which are safe and help to safe guard the human body from numerous illnesses including cancers too. This is due to the fact that cottonseed oil helps in the absorption of vitamin $\mathrm{E}$ in the body and which is turn is known to avoid some forms of cancer too [7].

\section{Maintains blood pressure}

The presence of mono- and polysaturated fats like oleic acid and linoleic acid in cottonseed have been seen to have an optimistic effect on reducing the chances of blood pressure in humans and regulates the same as well. It is also very important in maintaining heart health [7].

\section{Improves neurological health and memory}

Cottonseed is also a very important source of vitamin antioxidant, i.e. vitamin E. Hence, Paruthi Paal positively helps in the functioning of the nervous system and hence improving the memory functions [7].

The beneficial effects which are mentioned need a scientific basis as a proof. These beneficial effects are based on the traditional knowledge of the residents of Tamil Nadu and also from the internet sources.

\section{Conclusion}

In this article, we have seen a detailed process of Paruthi Paal preparation which is a main herbal or ethnic drink of Tamil Nadu, India. Paruthi Paal contains cottonseed milk as a main ingredient which is a rich source of protein, good fat and fibres. The study also developed a process of cottonseed milk preparation. The developed ready-to-serve product "Paruthi Paal" can also serve as a protein supplement for the prevention of malnutrition. Cottonseed milk is indeed a novel product that can be commercialised in India. Apart from health supplement, Paruthi Paal has several other beneficial effects such as acting as an antioxidant, prevents from heart-related problems, prevents stomach ulcers and many more. While preparing Paruthi Paal, it should be ensured that glandless cottonseeds are used, as excessive presence of gossypol which is present glanded varieties of cotton may cause toxicity.

\section{Acknowledgements}

Poongodi's Kitchen is highly acknowledged for providing insights into the preparation of traditional Paruthi Paal.
Authors' contributions

MK has contributed to the paper and has never submitted the manuscript, in whole or in part, to other journals. The author has read and approved the final manuscript.

\section{Funding}

This research did not receive any specific grant from funding agencies in the public, commercial, or not-for-profit sectors.

Availability of data and materials

All data and materials are presented in the manuscript.

Competing interests

The author declares that he has no competing interests.

Received: 22 July 2019 Accepted: 4 December 2019

Published online: 30 December 2019

References

1. Reed DA. Hearings: United states government printing office; 1953. (Google books Accessed 29/11/2019)

2. Amudha J. Cottonseed milk and its products: Cotton statistics and news, Cotton Association of India; 2018. (http://www.cicr.org.in/pdf/pop_art/ cotton milk_amudha.pdf)

3. Petre A. 2017. Science-Backed Home Remedies for Ulcers. Healthline (Accessed 5/07/2019).

4. Danielle D. 2018. What to eat if you have PCOS. Medical news today (Accessed 10/07/2019)

5. Konstantinovsky M. Natural Treatments for PCOS. One Med. 2019;2 (Accessed 8 July 2019).

6. Covey H.C. 2008. African American slave medicine: herbal and non-herbal treatments. (Google books Accessed 11/07/2019)

7. Wilson D.R. 2018. is cottonseed oil good or bad for you? Healthline (Accessed 28 June).

\section{Publisher's Note}

Springer Nature remains neutral with regard to jurisdictional claims in published maps and institutional affiliations.

\footnotetext{
Ready to submit your research? Choose BMC and benefit from:

- fast, convenient online submission

- thorough peer review by experienced researchers in your field

- rapid publication on acceptance

- support for research data, including large and complex data types

- gold Open Access which fosters wider collaboration and increased citations

- maximum visibility for your research: over $100 \mathrm{M}$ website views per year

At $\mathrm{BMC}$, research is always in progress.

Learn more biomedcentral.com/submission
} 